\title{
A SUPRACONSTITUCIONALIDADE DOS TRATADOS INTERNACIONAIS SOBRE DIREITOS HUMANOS: A SUPERAÇÃO DO MODELO CONSTITUCIONALISTA MODERNO E DA SOBERANIA DO ESTADO
}

\author{
SUPRACONSTITUTIONALITY OF HUMAN RIGHTS TREATIES: \\ THE OVERCOMING OF THE MODERN CONSTITUTIONAL MODEL AND THE \\ STATE'S SOVEREIGNTY
}

\author{
FRANCISCO ANTONIO NIERI MATTOSINHO \\ Mestrando do Programa de Mestrado em Ciência Jurídica da Universidade Estadual do Norte do Paraná (2015- \\ 2016). Bacharel em Direito pela Universidade Estadual do Norte do Paraná (2010-2014)
}

mattosinho_17@hotmail.com

\begin{abstract}
RENATO BERNARDI
Bacharel em Direito pela Instituição Toledo de Ensino - ITE (1992), Mestre em Direito Constitucional pela Instituição Toledo de Ensino - ITE (2003) e Doutor em Direito do Estado (sub-área Direito Tributário) pela Pontifícia Universidade

Católica de São Paulo - PUC-SP (2009). Professor efetivo do curso de Pós-Graduação stricto sensu - Mestrado - e do curso de Graduação da Faculdade de Direito do Centro de Ciências Sociais Aplicadas da Universidade Estadual do Norte do Paraná - UENP, Campus de Jacarezinho. Coordenador do PROJURIS Estudos Jurídicos Ltda. Professor dos cursos de pós-graduação lato sensu - Especialização - do PROJURIS/FIO. Coordenador do TCC no CCSA-UENP, campus de Jacarezinho, Coordenador de Extensão no CCSA-UENP, campus de Jacarezinho, Coordenador da Comissão de Extensão do campus da UENP de Jacarezinho, Membro do Comité de ética em pesquisa com seres humanos da UENP, Membro da Comissão de Coordenação do Programa de Mestrado em Ciência Jurídica no CCSA-UENP, campus de Jacarezinho, Membro do Conselho Curador da Escola Superior da Procuradoria Geral do Estado de São Paulo. Procurador do Estado de São Paulo desde 1994 reraber@gmail.com
\end{abstract}

\section{RESUMO}

O presente trabalho objetiva apresentar a superação do modelo constitucionalista moderno e da soberania do Estado, a fim de se reconhecer a natureza supraconstitucional dos tratados internacionais sobre direitos humanos. A partir da análise bibliográfica da construção teórica sobre a qual se funda o atual modelo constitucional, analisa-se a legitimidade material da constituição, a soberania e o futuro do Estado, a internacionalização dos direitos humanos e a relação entre a Constituição da República Federativa do Brasil de 1988 e o jus cogens. Conclui-se que, com o reconhecimento da supraconstitucionalidade dos tratados internacionais sobre direitos humanos, podese, efetivamente, avançar de um Estado Democrático de Direito, para um Estado Democrático e Humanitário de Direito Internacional.

Palavras-chave: Direito Internacional dos Direitos Humanos; Soberania; Tratados Internacionais.

\begin{abstract}
The current article aims to present the overcoming of the modern constitutional model and the State's sovereignty, recognizing the supraconstitutional nature of the international human rights treaties. Starting from the bibliographical analysis of the theoretical construction of the current constitutional model is built, the material legitimacy of the constitution is analyzed, the State's sovereignty and future, the internationalization of human rights and the linking between 1988 Federative Republic of Brazil Constitution and jus cogens. It concludes that the recognizing of supraconstitutionality of international human rights treaties may permit an effective progress from a Democratic Rule-of-Law State to a Democratic Rule-of-Humanitarian-and-InternationalLaw State.
\end{abstract}

Keywords: International Treaties; International Human Rigths Law; Sovereignty. 


\section{SUMÁRIO}

INTRODUÇAO; 1 A LEGITIMIDADE MATERIAL DA CONSTITUIÇÃO: A CONSTRUÇÃO DO CONSTITUCIONALISMO MODERNO E A INSERÇÃO DOS DIREITOS FUNDAMENTAIS NO CORPO DA CONSTITUIÇÃO; 2 A SOBERANIA DO ESTADO: O PRINCÍPIO LEGITIMADOR DO ESTADO; 3 O FUTURO DO ESTADO: BREVE VISITA ÀS PERSPECTIVAS FUTURISTAS; 4 A INTERNACIONALIZAÇÃO DOS DIREITOS HUMANOS: A TRANSPOSIÇÃO DO EIXO DE PROTEÇÃO DOS DIREITOS HUMANOS E A SUA FUNDAMENTAÇÃO; 5 A CONSTITUIÇÃO DA REPÚBLICA FEDERATIVA DO BRASIL DE 1988 E O JUS COGENS: ANÁLISE DA SUPRACONSTITUCIONALIDADE DOS TRATADOS SOBRE DIREITOS HUMANOS; CONCLUSÃO; REFERÊNCIAS.

\section{INTRODUÇÃO}

O estudo da formação do Estado perpassa pela compreensão da legitimação material da Constituição como instrumento normativo fundamental que o estrutura, o limita, garante direitos fundamentais e articula os objetivos que institui em seu corpo. Constitucionalistas de diferentes origens teorizam sobre o seu conceito.

Ferdinand Lassale entende que o texto fundamental representa o efetivo poder social, simbolizando a soma dos fatores reais do poder dentro de uma sociedade. Carl Schmitt aduz que representa o produto de uma decisão política do titular do poder constituinte, o povo. Hans Kelsen defende que ela constitui fruto da vontade racional do homem, revelando-se, no sentido lógico-jurídico, como norma fundamental hipotética, cuja função é servir de fundamento lógico transcendental da validade da Constituição jurídico-positiva, que equivale à norma positiva suprema, tendo origem no plano do suposto. José Horário Meirelles Teixeira ${ }^{1}$ afirma ser a Constituição produto de um fato cultural produzido pela sociedade e que sobre ela pode influir, a partir da fusão de fatores reais, espirituais, racionais e voluntaristas.

Em que pesem as construções teóricas que buscam compreender a formação do texto fundante do Estado Moderno, faz-se necessária uma releitura da posição hierárquico-normativa dos textos constitucionais e principalmente da influência que a comunidade internacional e as fontes consuetudinárias e normativas internacionais produzem sobre o modelo constitucional moderno.

\footnotetext{
${ }^{1}$ Curso de direito constitucional. Rio de Janeiro: Forense, 1991, p. 58-59.
} 
No contexto contemporâneo de universalização dos direitos humanos, fundado no compromisso internacional dos Estados soberanos de respeitarem os direitos e garantias basilares de seus cidadãos, com o objetivo de atingir os ideais de solidariedade característicos da terceira geração ou dimensão de direitos fundamentais, o modelo de soberania intangível e inafastável não mais pode servir como óbice e escusa para se negar a vinculação dos ordenamentos jurídicos estatais aos compromissos internacionais por eles assumidos.

A partir do marco de internacionalização dos direitos humanos mais preciosos da espécie humana, com vistas à proteção e à efetivação do postulado da dignidade da pessoa humana como instituto axial das situações jurídicas estatais, deve-se pensar num modelo em que a Constituição não mais ocupa o ápice da pirâmide normativa de um Estado soberano. Deve-se, na verdade, pensar que, apesar de ser expressão do poder social, somatória dos fatores reais de poder $^{2}$, decisão política de um povo ${ }^{3}$, fruto da vontade racional do homem ${ }^{4}$ ou produto de um fato cultural produzido pela sociedade que pode ser por ela influenciado, a Constituição deve pautar-se e adequar-se àquilo que o Estado, no exercício de sua soberania, concordou em se submeter perante os demais agentes internacionais, primando pelo postulado da cooperação, da boa-fé e do pacta sunt servanda dos tratados internacionais.

Assim, parte-se da análise bibliográfica da legitimidade material do texto Constitucional e toda a construção clássica até o momento erigida para sua compreensão, passando pela compreensão da mudança paradigmática testemunhada na metade do século XX e culminando na necessidade de se compreender os tratados internacionais sobre direitos humanos, aos quais a República Federativa do Brasil aderiu, como normas oriundas de jus cogens de natureza e hierarquia supraconstitucional.

\section{A LEGIMITIDADE MATERIAL DA CONSTITUIÇÃO: A CONSTRUÇÃO DO CONSTITUCIONALISMO MODERNO E A INSERÇÃO DOS DIREITOS FUNDAMENTAIS NO CORPO DA CONSTITUIÇÃO}

\footnotetext{
${ }^{2}$ Que é uma constituição? São Paulo: Edições e Publicações Brasil, 2006.

3 Teoría de La Constitución. Presentación de Francisco Ayala. Primera edición en "Alianza Universidad Textos" 1982. Cuarta reimpresión en "Alianza Universidad Textos”. Madrid. España. 2003.

${ }^{4}$ Teoria pura do direito. Tradução de João Baptista Machado. 6. Ed. Coimbra: Arménio Amado, 1984. 484p. (Coleção Stvdivm; Temas filosóficos, jurídicos e sociais).
} 
A SUPRACONSTITUCIONALIDADE DOS TRATADOS INTERNACIONAIS SOBRE DIREITOS HUMANOS: A SUPERAÇÃO DO MODELO CONSTITUCIONALISTA MODERNO E DA SOBERANIA DO ESTADO

O modelo constitucionalista moderno surge a partir do ideal filosófico iluminista que influenciou diretamente as revoluções americana e francesa do final do século XVIII. A forma de um texto fundamental escrito e positivado surge com esses movimentos, mas a gênese do espírito constitucional, na verdade, deve ser atribuído ao sistema anglo-saxão.

Desde a imposição da Magna Carta ao rei João Sem-Terra, no século XIII, tem-se a delimitação do poder do soberano, a estruturação do Estado e a acanhada e seletiva ${ }^{5}$ previsão de direitos e garantias fundamentais aos súditos, afastando a arbitrariedade e o poder despótico em nome de situações basilares que devem ser observadas nas relações entre Estado e cidadãos.

A compreensão anglo-saxã de constitucionalismo revela como essa formação do Estado juridicamente limitado e desenhado prescinde de uma carta escrita. Charles Howard Mcllwain ${ }^{6}$, citando a definição apresentada por Lorde Bolinbroke, inicia sua análise sobre o constitucionalismo antigo e moderno:

Por constituição queremos dizer, quando falamos com propriedade e exatidão, o conjunto de leis, instituições e costumes deduzidos de determinados princípios racionais tendentes a determinados objetos do bem comum, que integram o sistema geral conforme ao que a coletividade concordou para ser governada. A isto chamamos bom governo, isso é... quando o conjunto da Administração dos assuntos públicos se verifica com prudência e com submissão estrita aos princípios fins da constituição. ${ }^{7}$

Nota-se que a ideia de constituição é anterior ao próprio governo legitimamente reconhecido. Essa é a máxima política do direito anglo-saxão e não um princípio fundante do Estado, que, nesse contexto, é posterior à própria ideia constitucionalista. Os princípios de uma Constituição têm prioridade sobre os atos de qualquer governo, não porque são anteriores a eles no tempo, mas por conta de sua superioridade em capacidade de obrigar.

\footnotetext{
${ }^{5}$ Acanhada e seletiva, pois os direitos e garantias previstos na Carta Magna visavam a proteger somente os barões e o clero ingleses, não se estendendo a todos os súditos do Reino Unido. Nesse sentido: "Em que pese a sua forma de promessa unilateral, feita pelo rei, a Magna Carta constitui, na verdade, uma convenção passada entre o monarca e os barões feudais, pela qual se lhes reconheciam certos foros, isto é, privilégios especiais. Ela foi, por conseguinte, antes um foral do que um contrato de senhorio (Herrschaftsvertrag do direito medieval germânico; semelhante à constituição das capitanias hereditárias no Brasil colônia)." In: COMPARATO, Fábio Konder. A afirmação histórica dos direitos humanos. 9. Ed. São Paulo: Saraiva, 2015, p. 91.

${ }^{6}$ MCILWAIN, Charles Howard. Constitucionalismo antiguo y moderno. Traducción: Juan José Solozábal Echavarría. Centro de Estudios Constitucionales: Madrid, 1991, p. 17.

${ }^{7}$ Do original: Por constitución queremos significar, cuando hablamos con propriedade y exactitud, el conjunto de leyes, instituciones y costumbres deducidas de determinados princípios racionales tendentes a determinados objetos del bien común, que integran el sistema general conforme al que la colectividad ha acordado ser gobernada. A esto llamamos buen gobierno, esto es... cuando el conjunto de la Administración de los assuntos públicos se verifica com prudencia y con sometimiento estricto a los princípios fines de la constitución.
} 
A SUPRACONSTITUCIONALIDADE DOS TRATADOS INTERNACIONAIS SOBRE DIREITOS HUMANOS: A SUPERAÇÃO DO MODELO CONSTITUCIONALISTA MODERNO E DA SOBERANIA DO ESTADO

Sir Edward Coke ${ }^{8}$ defendia que todo o corpo completo da common law devia permanecer incólume se se desejava assegurar a liberdade do súdito contra o governo despótico. Pensava, todavia, à maneira dos medievalistas, atribuindo aos costumes um valor superior a de qualquer tipo de legislação.

Tida como texto fundamental eminentemente escrito ou anterior a qualquer forma estatal, qualquer seja a forma adotada (a partir de ideias filosóficas, como na França revolucionária, ou a partir da experiência prática política, no caso das colônias britânicas rebeldes) é certo que a maioria dos movimentos constitucionalistas têm seguido o modelo de textos fundamentais escritos que estabelecem, definem e limitam os governos.

[...] em todas suas fases sucessivas, o constitucionalismo tem uma essencial qualidade: implica uma limitação jurídica do governo; é a antítese do governo arbitrário; é o contrario do governo despótico, do governo do capricho ao invés do direito. Nos tempos modernos, a isso se tem acrescentado a expansão da responsabilidade através da consecução da iniciativa nas matérias discricionárias da política nacional dos representantes do Povo, como veremos logo, mas o diferencial característico mais antigo constante e duradouro do verdadeiro constitucionalismo continua sendo como tem sido quase desde o começo, a limitação do governo pelo direito. As limitações constitucionais, se não a mais importante parte do nosso constitucionalismo, são, sem dúvida, a mais antiga ${ }^{9}{ }^{10}$

Como apontado por Mcllwain, Estado e Constituição se relacionam de maneira intrínseca, tendo como linha tênue o momento em que se pode definir o surgimento de um ou de outro. O mesmo autor expõe que, mais tarde, a partir da sedimentação da ideia de constituição como moldura do Estado, é que foram acrescentadas as responsabilidades no bojo do texto fundamental, a fim de nortear as escolhas políticas dos representantes do povo.

Aponta-se como exemplo dessa evolução o próprio texto constitucional americano, de 1787, que inicia com os seguintes dizeres: “Nós, o povo dos Estados Unidos, a fim de formar a mais perfeita união, de estabelecer justiça, de assegurar tranquilidade interna, de promover a defesa de todos, de promover o bem-estar geral, e de assegurar as bênçãos da liberdade para

${ }^{8}$ COKE, Sir Edward. Parliamentary History. 1627. London: 11, p. 237.

${ }^{9}$ Do original: [...] en todas sus fases sucesivas, el constitucionalismo tiene una esencial cualidad: implica una limitación jurídica del gobierno; es la antítesis del gobierno arbitrario; es lo contrario del gobierno despótico, del gobierno del capricho en vez del derecho. En los tiempos modernos, a esto se ha añadido la expansión de la responsabilidad a través de la consecución de la iniciativa en las materias discrecionales de la política nacional de los representantes del Pueblo, como veremos luego, pero el rasgo característico más antiguo constante y duradero del verdadero constitucionalismo continua siendo como lo ha sido casi desde el comienzo, la limitación del gobierno por el derecho. Las limitaciones constitucionales, si no la más importante parte de nuestro constitucionalismo, son, fuera de duda, la más antigua.

${ }^{10}$ McILWAIN, Charles Howard. Op. cit., p. 37. 
A SUPRACONSTITUCIONALIDADE DOS TRATADOS INTERNACIONAIS SOBRE DIREITOS HUMANOS: A SUPERAÇÃO DO MODELO CONSTITUCIONALISTA MODERNO E DA SOBERANIA DO ESTADO

nós mesmos e para nossa posteridade, redigimos e promulgamos essa constituição para os Estados Unidos da América"11. Em seu corpo, formado por apenas sete artigos, a Constituição norte-americana trata do Poder Legislativo, do Poder Executivo, do Poder Judiciário, das relações do Estado, do processo de alteração por meio de emendas, das dívidas anteriores que foram assumidas pela União, a supremacia nacional e os juramentos de cumprimento da constituição tomados dos agentes políticos, e da ratificação da Constituição, prevendo ser necessária a adesão de, no mínimo, nove estados.

Em 1789, a Constituição Americana é alterada pela primeira vez, a fim de incluir a emenda conhecida como Bill of Rights. Trata-se de uma coletânea de dez emendas propostas para diminuir os temores dos anti-federalistas que haviam se posicionado contra a ratificação da Constituição. Essas emendas garantem liberdades pessoais, limitam o poder do governo em ações judiciais, e reservam alguns poderes aos estados federados e ao povo.

Em 8 de junho de 1789, James Madison apresentou uma série de trinta e nove emendas à Constituição na Câmara dos Deputados. Entre esses projetos, Madison propôs a abertura da Constituição para a inserção de direitos, que limitavam o poder do Congresso. Sete dessas limitações se tornariam parte das dez emendas aprovadas na Bill of Rights.

Em 25 de setembro de 1789, o Congresso acrescentou doze artigos à Constituição e os submeteu aos estados para ratificação. Ao contrário da proposta original de Madison para que os artigos fossem incorporados no corpo principal da Constituição, eles foram aprovados como artigos suplementares a ela.

No preâmbulo da Bill of Rights, pode-se ler:

Os representantes de alguns Estados, ao tempo de sua adesão à Constituição, expressaram o desejo, a fim de prevenir interpretações equivocadas ou abuso de seus poderes, que as seguintes cláusulas declaratórias e restritivas fossem adicionadas: E como extensão da confiança pública depositada no Governo, será melhor assegurar os melhores fins de sua instituição. Resolveram o Senado e a Câmara dos Deputados dos Estados Unidos da América, em sessão do Congresso, por dois terços de ambas as Casas, que os seguintes artigos são propostos aos Legislativos de vários Estados, como emendas à Constituição dos Estados Unidos; todos, ou quaisquer dos artigos, quando ratificados por três quartos dos Legislativos, serão válidos para todas as intenções e propósitos, como parte da mencionada Constituição. Os artigos adicionados e a emenda à Constituição dos Estados Unidos da América, propostos pelo Congresso, e ratificados pelos

\footnotetext{
${ }^{11}$ Do original: "We the People of the United States, in Order to form a more perfect Union, establish Justice, insure domestic Tranquility, provide for the common defense, promote the general Welfare, and secure the Blessings of Liberty to ourselves and our Posterity, do ordain and establish this Constitution for the United States of America".
} 
A SUPRACONSTITUCIONALIDADE DOS TRATADOS INTERNACIONAIS SOBRE DIREITOS HUMANOS: A SUPERAÇÃO DO MODELO CONSTITUCIONALISTA MODERNO E DA SOBERANIA DO ESTADO

Legislativos de vários Estados, nos termos do artigo quinto da Constituição original $^{12}$.

A Bill of Rights acrescentou, assim, direitos e garantias fundamentais ao texto original da Constituição norte-americana, a fim de garantir aos anti-federalistas a observância das liberdades dos Estados Federados, mantendo, com isso, a unidade sob aquele texto fundamental.

A partir da análise do texto norte-americano, como referência do constitucionalismo moderno ocidental, percebe-se que todo o ordenamento jurídico e toda a moldura estatal são dilapidados pela norma fundamental do Estado.

Alçada ao ápice do sistema jurídico por ser fruto da soberania estatal, consagrou-se a ideia da supremacia constitucional, não havendo, assim, norma ou força que a ela se sobreponha, pois, se houvesse, os fundamentos basilares estatais estariam se curvando perante a influência de outra força que não aquela emanada do titular do poder constituinte. Relacionamse, assim, os conceitos de supremacia constitucional com o de soberania do Estado, ideal que, se relativizado pela influência do direito internacional e das normas de jus cogens, principalmente em matéria de direitos humanos, conduzem à noção da supraconstitucionalidade dos tratados internacionais sobre direitos humanos ratificados pelos Estados soberanos.

\section{A SOBERANIA DO ESTADO: O PRINCÍPIO LEGITIMADOR DO ESTADO}

A soberania dos Estados modernos tem como gênese os tratados de paz conhecidos como Paz de Vestfália, estabelecidos no final da Guerra dos Trinta Anos, em 1648, e que marcaram a passagem da sociedade medieval para a sociedade do Estado Moderno. Ademais,

\footnotetext{
12 Do original: "The Conventions of a number of the States, having at the time of their adopting the Constitution, expressed a desire, in order to prevent misconstruction or abuse of its powers, that further declaratory and restrictive clauses should be added: And as extending the ground of public confidence in the Government, will best ensure the beneficent ends of its institution.

Resolved by the Senate and House of Representatives of the United States of America, in Congress assembled, two thirds of both Houses concurring, that the following Articles be proposed to the Legislatures of the several States, as amendments to the Constitution of the United States, all, or any of which Articles, when ratified by three fourths of the said Legislatures, to be valid to all intents and purposes, as part of the said Constitution; viz. Articles in addition to, and Amendment of the Constitution of the United States of America, proposed by Congress, and ratified by the Legislatures of the several States, pursuant to the fifth Article of the original Constitution".
} 
afirmaram três princípios fundamentais: a) o princípio da liberdade religiosa dos Estados, b) 0 princípio da soberania dos Estados, e c) o princípio da igualdade entre os Estados ${ }^{13}$.

A Paz de Vestfália consagrou o "reconhecimento oficial da ideia de uma sociedade internacional integrada por Estados iguais e soberanos"14. O conceito de soberania e a qualificação de soberano dada ao Estado desempenham um papel decisivo na solidificação do Estado Moderno. A partir do uso da força sobre um determinado território e população e do monopólio do direito, estrutura-se uma forma de organização do poder centrada numa autoridade legal suprema, detentora do poder originário, livre de intervenção interna ou externa. ${ }^{15}$

Um dos grandes teóricos sobre o conceito de soberania é o cientista político Jean Bodin (1530-1596). A par de sua obra desenvolver toda a evolução histórica e conceitual acerca do tema, o significado teórico da obra de Bodin para o direito político moderno não é outro senão de atribuir um caráter sistemático na discussão sobre Estado, o que se concretiza pela recuperação do processo de desenvolvimento, dos fundamentos teóricos e dos princípios que deram sustentação para a existência da soberania como elemento indispensável à organização da sociedade política ${ }^{16}$.

A soberania atribuída ao Estado apresenta dupla significação na teoria bodiana. Uma noção normativa, no sentido de que este poder soberano inclui o monopólio da força, o direito de legislar e aplicar a lei, ou seja, ele designa as aspirações do poder do Estado. É, também, um conceito descritivo, usado como elemento caracterizador do poder estatal.

Trata-se, na concepção de Bodin, de um poder absoluto, que significa, na sociedade política, estar acima das leis civis, assim como o soberano tem o poder de criar as leis civis e de alterá-las de acordo com a sua vontade. Em decorrência deste poder absoluto e perpétuo do Estado, emanam direitos de ordem exclusiva do soberano, que somente poder ser exercidos por seu titular ou possuidor. Assim, decorre da soberania o direito de declarar a guerra ou negociar a

\footnotetext{
${ }^{13}$ COLOMBO, Silvana. A relativização do conceito de soberania no plano internacional. In: Argumenta: Revista do Programa de Mestrado em Ciência Jurídica da Universidade Estadual do Norte do Paraná UENP. No 17. Jacarezinho/PR, 2012, p. 230

${ }^{14}$ BOSON, Gerson de Brito Mello. Direito Internacional Público: o Estado em direito das gentes. Belo Horizonte: Del Rey, 1994, 162.

${ }^{15}$ COLOMBO, Silvana. Op. Cit., p. 230.

${ }^{16}$ BODIN, Jean. Los seis libros de la república. 2. Ed. Tradução: Pedro Brava Gala. Madrid: Tecnos, 1992, I, 8.
} 
paz; o direito de instituir moedas, o direito de julgamento em última instância, o direito de conceder graças ao condenado e o direito de instituir e cobrar impostos ${ }^{17}$.

A definição normativa de soberania é a mais presente na sociedade internacional, pois os Estados, apesar das pressões que pretendem conduzi-los à integração internacional, buscam afirmar a jurisdição de forma exclusiva sobre um determinado território ${ }^{18}$.

Independentemente dos direitos que a soberania atribui ao Estado, é a afirmação deste poder como absoluto e perpétuo que revela a maior contribuição da obra de Bodin à formação do Estado Moderno. A soberania é una e indivisível, porque num mesmo Estado não se admite a convivência de duas soberanias, já que se configura como poder superior a todos os demais existentes na sociedade política.

Entretanto, mesmo que tenha definido a soberania como poder absoluto e perpétuo, Bodin não descarta os limites de ação do soberano. Em outras palavras, seu detentor não possui um poder arbitrário porque o soberano está sujeito às leis humanas comuns a todos os povos. Nesse ponto, percebe-se a influência dos ideias jusnaturalistas na teoria bodiana, permitindo concluir que o jurista francês já visualizava a flexibilização da soberania ao jus cogens.

Com relação à titularidade da soberania, apresentam-se duas teorias como aporte teórico: as teorias teocrática e democrática.

Segundo Norberto Bobbio ${ }^{19}$, as teorias teocráticas predominaram no fim da Idade Média, no momento em que se esboçava a soberania como elemento essencial do Estado Moderno. Elas têm como base em comum a afirmação de que todo o poder vem de Deus. De um lado, sustentavam que a soberania vem de Deus assim como todas as coisas terrenas. De outro lado, reconheciam que a soberania apresenta imperfeições porque decorre diretamente do povo.

Ainda segundo o autor ${ }^{20}$, as teorias democráticas, por sua vez, defendiam que a soberania origina-se do povo, apresentando-se na forma de três variações. Na primeira, o titular da soberania é o povo, situado fora do Estado. Na segunda, a partir da Revolução Francesa, é atribuída à nação a titularidade da soberania. E, por último, a consolidação do Estado como titular do poder soberano.

A doutrina da soberania popular encontra em Hobbes e Rousseau seus defensores. Essa doutrina tem como fundamento o princípio democrático, a igualdade política e o sufrágio

\footnotetext{
17 Idem.

${ }^{18}$ COLOMBO, Silvana. Op. Cit., p. 231.

19 BOBBIO, Norberto. Estado, governo e sociedade: para uma teoria geral da política. Tradução: Marco Aurélio Nogueira. Rio de Janeiro: Paz e Terra, 1995.

${ }^{20}$ Idem.
} 
A SUPRACONSTITUCIONALIDADE DOS TRATADOS INTERNACIONAIS SOBRE DIREITOS HUMANOS: A SUPERAÇÃO DO MODELO CONSTITUCIONALISTA MODERNO E DA SOBERANIA DO ESTADO

universal. Cada indivíduo detém uma parcela da soberania, que o permite participar ativamente na escolha de seus representantes ${ }^{21}$. Rousseau afirma: "se o Estado é composto por dez mil cidadãos, cada um terá a décima milésima parte da autoridade soberana” ${ }^{22}$.

Com relação à teoria de Hobbes, Fernando de Brito Alves assinala em sua obra:

Sem dúvida, as grandes teorias do Estado se iniciam a partir das proposições de Thomas Hobbes. Ele apresenta sua teoria do Estado no Leviatã, todavia, antes de pensar o Estado, o autor elabora uma teoria da sociedade civil na obra De Cive. Isso é um indício de que, para Hobbes, é impossível pensar o Estado sem antes pensar a sociedade civil. O Estado, portanto, tem uma configuração atomística. Embora o pacto que o constitua não possa ser revisto, e o soberano, como guardião do pacto, não se submeta a ele, o Estado que nasce dele é a soma positiva de todos os cidadãos, de todos os pactuantes. O Leviatã não é imagem do Estado, mas do soberano. 0 Estado é um mosaico, que tem uma tendência intrínseca a se desagregar e retornar ao estado de natureza. A solução hobbesiana para que o retorno a desregulação não ocorra é sacrificar a liberdade, para que haja alguma igualdade. ${ }^{23}$

No período da Revolução Francesa, a doutrina democrática fez prevalecer a teoria da soberania nacional. 0 indivíduo como titular de uma fração da soberania cede espaço para a Nação, titular exclusiva do poder soberano. 0 artigo $3^{\circ}$ da Declaração dos Direitos do Homem afirma essa ideia: “O princípio de toda a soberania reside essencialmente na Nação e nenhuma corporação, nenhum indivíduo pode exercer autoridade que dela não emane expressamente”24.

Além das teorias apresentadas, a soberania também deve ser analisada a partir do prisma externo e interno. Por meio do prisma do direito internacional, observa-se a soberania como um dado essencial constitutivo do Estado. Há Estados soberanos e Estados não soberanos. A partir desse ponto, a soberania é apenas qualidade do poder, que a organização estatal poderá ostentar ou deixar de ostentar. Do ponto de vista interno, por sua vez, a soberania, como conceito jurídico e social, se apresenta menos controvertida, pois, como visto, é da essência do ordenamento estatal uma superioridade e supremacia, a qual, resumindo, já a noção de soberania, faz que o poder do Estado se sobreponha incontrastavelmente aos demais poderes sociais, que thes ficam subordinados. A soberania assim entendida como soberania interna fixa a

\footnotetext{
${ }^{21}$ COLOMBO, Silvana. Op. Cit., p. 233-234.

22 ROUSSEAU, Jean Jacques. Do contrato social: Princípios do direito político. São Paulo: Revista dos Tribunais, 2003, p. 52.

${ }^{23}$ ALVES, Fernando de Brito. Constituição e participação popular: a construção histórico-discursiva do conteúdo jurídico-político da democracia como direito fundamental. Curitiba: Juruá, 2013, p. 55.

${ }^{24}$ Do original: "Le principe de toute Souveraineté réside essentiellement dans la Nation. Nul corps, nul individu ne peut exercer d'autorité qui n'en émane expressément".
} 
A SUPRACONSTITUCIONALIDADE DOS TRATADOS INTERNACIONAIS SOBRE DIREITOS HUMANOS: A SUPERAÇÃO DO MODELO CONSTITUCIONALISTA MODERNO E DA SOBERANIA DO ESTADO

noção de predomínio que o ordenamento estatal exerce num certo território e numa determinada população sobre os demais ordenamentos sociais ${ }^{25}$.

A soberania tem como fundamento a ordem intra-estatal e interestatal. De um lado, o Estado é soberano porque é a instância superior dentro de um território limitado, aplicando-se às pessoas de uma dada nacionalidade. Por outro, a soberania nas relações interestatais pressupõe a exclusão da sujeição a uma única autoridade ${ }^{26}$. 0 conceito de soberania que tem como fundamento a ordem intra-estatal é, nas palavras de Aron, "inútil, pelo fato de que representa apenas a validade de um sistema de normas num espaço determinado". No entanto, na ordem interestatal, ela é nociva porque "os imperativos jurídicos retiram sua força obrigatória da vontade dos poderes do Estado" ${ }^{27}$.

A afirmativa de que a soberania intra-estatal é diferente da soberania interestatal implica, no primeiro caso, na sujeição a um poder soberano e, no segundo, na independência dos Estados igualmente soberanos. Significa dizer que na soberania externa, cada unidade política não aceita uma autoridade externa, apenas se submete às suas próprias leis e vontades ${ }^{28}$.

No entanto, verifica-se a crise desse conceito na contemporaneidade, principalmente após a segunda metade do século XX.

De uma parte, a dificuldade de conciliar a noção de soberania do Estado com a ordem internacional, de modo que a ênfase na soberania do Estado implica sacrífico maior ou menor do ordenamento internacional e, vice-versa, a ênfase neste se faz com restrições de grau variável aos limites da soberania, há algum tempo tomada ainda em termos absolutos; doutra parte, a crise se manifesta sob o aspecto e a evidência de correntes doutrinárias ou fatos que ameaçadoramente patenteiam a existência de grupos e instituições sociais concorrentes, as quais disputam ao Estado sua qualificação de ordenamento político supremo, enfraquecendo e desvalorizando por consequência a ideia mesma do Estado. ${ }^{29}$

Como se percebe, o conceito de soberania como apresentado, fundado no exercício do poder jurídico-normativo pelo Estado que se materializa no postulado do texto constitucional como norma fundamental e suprema passa por larga e minuciosa revisão, que deve ser enfrentada com zelo e acuidade, a fim de não se ignorar as construções teóricas até então

\footnotetext{
${ }^{25}$ BONAVIDES, Paulo. Ciência política. 16. Ed. Malheiros Editores: São Paulo, 2010, p. 132.

${ }^{26}$ ARON, Raymond. Paz e guerra entre as nações. Tradução de Sérgio Bath. 2. Ed. Brasília: UnB, 1996, p. 886.

${ }^{27}$ Idem, p. 86.

${ }^{28}$ COLOMBO, Silvana. Op. cit., p. 235.

${ }^{29}$ BONAVIDES, Paulo. Op. cit., p. 133.
} 
A SUPRACONSTITUCIONALIDADE DOS TRATADOS INTERNACIONAIS SOBRE DIREITOS HUMANOS: A SUPERAÇÃO DO MODELO CONSTITUCIONALISTA MODERNO E DA SOBERANIA DO ESTADO

apresentadas e relativizar um conceito essencial e intrínseco à própria formação do Estado como agente internacional.

Atualmente, as ideologias pesam mais nas relações entre os Estados do que o sentimento nacional de soberania. Nesse sentido:

Produzem as ideologias tamanha solidariedade entre indivíduos de países diferentes que acabam por estreitá-los num vínculo de consciência mais apertado que o laço de nacionalidade. Muitas vezes, contemporaneamente, diz Duverger, exprimindo essa mesma ideia, numa análise de surpreendente acuidade, indivíduos de Estados distintos atuam com mais compreensão e entendimento, à base de convicções políticas idênticas, do que tangidos por motivos de ordem pátria ${ }^{30}$. Diz isso o pensador francês para mostrar como os fundamentos nacionais da soberania hão sido acometidos e enfraquecidos por fatores diversos na hora presente. Outro motivo que concorre fortemente para abater o princípio de soberania é a necessidade de criar uma ordem internacional, vindo essa ordem a ter um primado sobre a ordem nacional. Os internacionalistas são homens que veem sempre com suspeição o princípio da soberania. Não apenas com suspeição, senão como se fora ele obstáculo à realização da comunidade internacional, à positivação do direito internacional, à passagem do direito internacional, de um direito de bases meramente contratuais, apoiado em princípios de direito natural, de fundamentos tão-somente éticos ou racionais, a um direito que coercitivamente pudesse impor a todos os Estados. ${ }^{31}$

A soberania na ordem internacional significa independência. O sistema internacional não se subordina a um sistema legal ou a um imperativo ético absoluto, razão pela qual a definição de soberania no plano externo tem uma significação diferenciada que torna problemática a conformação do seu conceito enquanto poder absoluto.

Se a soberania na ordem interna serve para justificar em cada Estado uma forma de governo, o poder de certas instâncias ou de certas pessoas, na ordem externa está diretamente ligado à não-dependência. Portanto, nas relações interestatais, vigora a teoria do Direito Internacional. ${ }^{32}$

Nenhum observador do Direito Internacional moderno e do desenvolvimento histórico da noção de soberania pode ignorar as transformações que o referido termo tem sofrido de forma mais contundente no decorrer deste século. A ideia de absolutização e perpetuidade da soberania, abordada pela primeira vez por Jean Bodin, se esvazia diante das normas internacionais jus cogens, isto é, normas que vinculam os Estados de forma imediata.

\footnotetext{
30 DUVERGER, Maurice. Droit constitutionel et institutions politiques. P. 72-73. In: BONAVIDES, Paulo. Ciência política. 16. Ed. Malheiros Editores: São Paulo, 2010, p. 143.

${ }^{31}$ BONAVIDES, Paulo. Op. Cit., p. 143.

${ }^{32}$ COLOMBO, Silvana. Op. Cit., p. 236.
} 


\section{O FUTURO DO ESTADO: BREVE VISITA ÀS PERSPECTIVAS FUTURISTAS}

Se o Direito Internacional nos seus primórdios se desenvolveu em termos de soberania, com o fim de regular a coexistência entre as unidades políticas soberanas, à medida que se reduzem as fronteiras físicas da humanidade e que crescem os problemas de ordem global, torna-se cada vez mais necessária a primazia dos direitos do homem sobre a soberania nacional.

Ferrajoli prima por "um direito internacional fundamentado na soberania dos Estados, mas na autonomia dos povos: a humanidade no lugar dos Estados; um constitucionalismo mundial, inclusive com garantias jurisdicionais globais, no posto ou ao lado dos constitucionalismos nacionais" ${ }^{33}$.

Após as duas grandes guerras mundiais, cresce a necessidade de se repensar o modelo de soberania estatal até então dominante e que, dentre outros fatores, legitimou a prática de atrocidades contra a humanidade, em nome da supremacia das ordens constitucionais.

A Carta das Nações Unidas, de 1945, ilustra de maneira clara a preservação que o Direito Internacional reserva à soberania e, ao mesmo tempo, à cooperação internacional entre os Estados quando prevê, em seu artigo 2.1, que "a Organização (das Nações Unidas) é baseada no princípio da igualdade de todos os seus Membros". Bobbio, em sua obra, lembra que "todo Estado existe ao lado de outros estados numa sociedade de Estados" ${ }^{34}$.

No continente americano, a Carta da Organização dos Estados Americanos criou aquela organização, em 30 de abril de 1948, e estabelece em seu artigo 1, dentre a sua natureza e os seus propósitos, que “os Estados americanos consagram nesta Carta a organização internacional que vem desenvolvendo para conseguir uma ordem de paz e de justiça, para promover sua solidariedade, intensificar sua colaboração e defender sua soberania, sua integridade territorial e sua independência”.

Percebe-se que, ao mesmo tempo em que se protege o conceito do poder soberano dos Estados em relação à sua integridade territorial, autodeterminação e formulação jurídiconormativa, surge a perspectiva futura da construção de uma comunidade internacional juridicamente homogênea, num primeiro momento, em relação às regras aplicáveis às relações entre os Estados soberanos e, em seguida, à proteção da humanidade de maneira universal.

\footnotetext{
${ }^{33}$ FERRAJOLI, Luigi. A soberania no mundo moderno. São Paulo: Martins Fontes, 2003, p. 7.

${ }^{34}$ BOBBIO, Norberto. A era dos direitos. Rio de Janeiro: Campus, 2004, p. 101.
} 
A SUPRACONSTITUCIONALIDADE DOS TRATADOS INTERNACIONAIS SOBRE DIREITOS HUMANOS: A SUPERAÇÃO DO MODELO CONSTITUCIONALISTA MODERNO E DA SOBERANIA DO ESTADO

Os próprios Estados soberanos revelam, por meio da formação de tratados internacionais universais e regionais, suas preocupações com as perspectivas futuras. Estabelecendo documentos jurídicos internacionais, fundados no debate e na concordância acerca de temas comuns, eles mesmos demonstram tendência a relativizar sua soberania. Afinal, ratificar um documento normativo cuja origem reside em ideais universais ou regionais, que são frutos das mais diversas concepções e do próprio direito das gentes (jus cogens), simboliza, ainda que implicitamente, que os Estados estão conscientes de que, num futuro não muito distante, sujeitar-se-ão a uma normativa jurídica internacional comum supraconstitucional. Esse tema, no entanto, deve ser tratado com o respeito e acatamento científicos necessários.

A predição de comportamentos sociais, em especial daqueles que afetam diretamente a organização e o funcionamento do Estado, é uma das tarefas mais relevantes da Teoria do Estado. Com efeito, ninguém há de procurar conhecer o Estado, desde suas origens até sua atual situação, com toda a extraordinária complexidade que ele adquiriu através dos séculos, a não ser para a obtenção de uma orientação mais segura quanto aos comportamentos futuros. Mesmo quando se atém ao estudo da atualidade do Estado e dos fenômenos sociais que podem influir sobre ele, a Teoria do Estado procede a uma verificação de tendências e possibilidades, a partir de elementos cientificamente coligidos e obedecendo a uma metodologia também científica, culminando sempre numa avaliação de probabilidades. ${ }^{35}$

$\mathrm{Na}$ medida em que se teoriza e se defende a necessidade de os Estados reconhecerem, não só implicitamente como também explicitamente, a vinculação de suas ordens normativas aos tratados internacionais aos quais soberanamente se submetem, deve-se lembrar, também, que não se estabelece situação inédita na história do desenvolvimento das nações. Como o predomínio de uma lei universal em todos os Estados era buscada pelos juristas, sua realização importaria na unificação jurídica universal, ficando, entretanto, em aberto o problema do órgão de poder político central. Tome-se, como exemplo, a existência dos grandes impérios ao longo da história da humanidade: Império Macedônico, Império Persa, Império Romano, Califado Omíada, Império Mongol, Império Otomoano, Império Bizantino, Sacro-Império RomanoGermânico, Império Português, Império Espanhol, Império Francês e mais recentemente Império Russo e Império Inglês.

No século XX, a ideia de uma organização política mundial dotada de um centro de poder superior ao dos Estados passou a ser considerada em termos de possibilidade, por juristas e teóricos da política, a partir da Segunda Guerra Mundial ${ }^{36}$, que abalou aquele século e marcou

\footnotetext{
${ }^{35}$ DALLARI, Dalmo de Abreu. O futuro do Estado. 2. Ed. São Paulo. Saraiva, 2007 p. 38-39.

${ }^{36}$ DALLARI, Dalmo de Abreu. Op. cit., p. 87.
} 
A SUPRACONSTITUCIONALIDADE DOS TRATADOS INTERNACIONAIS SOBRE DIREITOS HUMANOS: A SUPERAÇÃO DO MODELO CONSTITUCIONALISTA MODERNO E DA SOBERANIA DO ESTADO

a história da humanidade. Analisando o passado para localizar as causas das guerras e fazendo predições, baseadas na consideração de futuros prováveis em face dos comportamentos anteriores, muitos chegaram à conclusão de que o egoísmo dos Estados e sua possibilidade de uso arbitrário da força precisavam ser restringidos ou eliminados ${ }^{37}$.

0 que se verifica, no atual contexto das relações internacionais, é que os Estados caminham, ainda que em passos peculiares a cada região do planeta, para um futuro de superação do modelo internacional, numa visão universal das relações entre as soberanias.

Outro aspecto constantemente referido é o relacionado com a forma que poderia ou deveria adotar o futuro Estado mundial. Também a esse respeito muitas são as opiniões, predominando, entretanto, a ideia de que o mais adequado seria um grande Estado federal único, transpondo-se para o plano mundial o tipo de relacionamento que já existe atualmente nos Estados federais. Mortimer Adler considera a federação de Estados a forma ideal, por ser a que menos interfere na liberdade política, moral e cultural de cada povo. Isso não quer dizer que o Estado mundial não devesse dispor de meios para assegurar coercitivamente o cumprimento das decisões de seus órgãos de governo. Preservadas as liberdades fundamentais, a organização mundial não seria, segundo suas expressões, meramente governamental, ou seja, não seria o produto da adoção de um governo comum, mas, em lugar disso, teria por fundamento a plenitude política. Em outras palavras, a Federação Mundial de Estados, governada por um Conselho Consultivo Supranacional, que encarregaria os governos nacionais da execução de suas decisões, seria baseada na vontade de viver em comum, de todos os povos. ${ }^{38}$

Dentre os internacionalistas, essa possibilidade de um Estado mundial é viável, desde que, de maneira imprescindível, se adote, alternativamente, duas posturas: ou o reconhecimento da superioridade do Direito Internacional ou a criação de condições para assegurar a eficácia de uma ordem jurídica mundial.

Hans Kelsen enfrenta o problema, indicando três pressupostos necessários para que esse objetivo se materialize: i) é preciso que seja reconhecida pelos Estados a supremacia do Direito Internacional, uma vez que a própria criação do Estado mundial se fará acima dos Estados e enquanto estes existirem; ii) os Estados devem abrir mão de sua soberania; iii) é preciso ter consciência de que, criado o Estado mundial, desaparecem as diferenças entre os atuais Estados e as sociedades que os integram, uma vez que aqueles deixam de ser soberanos ${ }^{39}$. Pelas premissas de Kelsen, percebe-se que o Estado deve ser reconhecido essencialmente como uma ordem jurídica.

${ }^{37}$ Idem, p. 83.

38 DALLARI, Dalmo de Abreu. Op. Cit., p. 90.

39 KELSEN, Hans. Teoría general del Estado. Traducción: Eduardo Gacía Máynez. Universidade Nacional Autónoma de México, 1988, p. 162. 
Hermann Heller também conclui que o principal problema para a criação de um Estado mundial é assegurar a eficácia de sua ordem jurídica. Em sua opinião, a criação da Sociedade das Nações, da Corte Internacional de Justiça e de uma jurisdição internacional já deu origem a um conflito insolúvel entre a soberania dos Estados e o Direito Internacional efetivamente eficaz ${ }^{40}$.

Outro modelo pensado para o futuro dos Estados foi a da formação de Grandes Federações.

\begin{abstract}
A ideia de agrupamento dos povos em federações, compondo um mundo de super-Estados federais, nasceu menos pretensiosa, pois os primeiros que a expuseram tinham como objetivo uma união europeia e só mais tarde chegaram à concepção de outras uniões semelhantes. De qualquer forma, entretanto, ainda que discutindo a conveniência de cuidar primeiro do problema europeu ou concomitantemente de todos os povos, muitos autores deixaram patente sua crença num conjunto de federações, abrangendo o mundo todo, como solução ideal para um sistema político mundial. ${ }^{41}$
\end{abstract}

Apesar de não haver nenhuma conformação dessas elencadas em plena concretização, atualmente, surgem como modelos a serem analisados e compreendidos aqueles vigentes na União Europeia. Tratam-se do Direito da Integração e do Direito Comunitário.

A integração regional é uma das modalidades de cooperação que os Estados vêm desenvolvendo no decorrer da história. Caracteriza-se pela aproximação dos Estados que apresentam certo grau de homogeneidade cultural, econômica e política e que se encontram em região geográfica próxima que lhes permite estreitar os laços e agir de maneira mais uniforme possível.

0 atual estágio do regionalismo atrai Estados em diferentes situações de desenvolvimento, criando espaços mais ou menos institucionalizados e com objetivos que variam da mera promoção de interesses no âmbito econômico-comercial à integração mais profunda, atingindo os campos político e social, limitando vigorosamente a soberania estatal. Normalmente, os mecanismos de integração regional são regulados pelo Direito da Integração, ramo do Direito Internacional que rege o funcionamento dos blocos regionais. Entretanto, dependendo do aprofundamento da integração, o processo integracionista pode vir a ser regulado por um novo ramo do fenômeno jurídico, o Direito Comunitário, que sempre se sobrepõe aos próprios direitos nacionais e que é diretamente aplicável dentro dos Estados, sem

\footnotetext{
${ }^{40}$ HELLER, Hermann. Teoría del Estado. 2. Ed. México, Fondo de Cultura Económica, 1947, p. 227.

${ }^{41}$ DALLARI, Dalmo de Abreu. Op. Cit., p. 131.
} 
formalidades de incorporação das normas do Direito Internacional Clássico ao ordenamento interno ${ }^{42}$.

O Direito Comunitário é o ramo do Direito que regula mecanismos de integração regional que atingiram um estágio de desenvolvimento mais aprofundado e que é criado não só pelos Estados, mas também pelos órgãos do bloco regional, sendo ainda marcado pela aplicabilidade imediata dentro dos entes estatais e pela superioridade hierárquica em relação ao Direito interno dos Estados. ${ }^{43}$

Nota-se que o atual estágio de desenvolvimento e da relativização da soberania dos Estados passa por um momento intermediário. Não se tem, ainda, um Estado mundial, mas já há formações regionais, cuja inspiração primordial no modelo europeu, permite sustentar o modelo proposto de supraconstitucionalidade de ordens jurídicas.

Para além dos interesses econômicos e políticos envolvidos e que, ao longo da história, sempre se relacionaram com a própria evolução jurídica, como bem desenvolveu Luhmann ${ }^{44} \mathrm{em}$ sua teoria sobre a sociedade como um sistema autopoiético, o fortalecimento do Direito Internacional na segunda metade do século XX deu-se, principalmente, em razão da transposição do eixo de defesa dos direitos humanos, passando da positivação em cartas de direitos fundamentais, como a Bill of Rights, para a internacionalização dos direitos humanos. Eis o primeiro passo para o reconhecimento da supraconstitucionalidade dos tratados internacionais sobre a matéria, vinculando os Estados que aderem, por meio do exercício de sua soberania, às convenções internacionais.

\section{A CONSTITUIÇÃO DA REPÚBLICA FEDERATIVA DO BRASIL DE 1988 E 0 JUS COGENS: ANÁLISE DA SUPRACONSTITUCIONALIDADE DOS TRATADOS DE DIREITOS HUMANOS}

O contexto latino-americano da segunda metade do século XX é marcado pela presença de Estados notadamente autoritários e conservadores que viviam à sombra da influência dos

\footnotetext{
42 PORTELA, P. H. G. Direito internacional público e privado: incluindo noções de direitos humanos e de direito comunitário. 7. Ed. rev., ampl., e atual. Editora Juspodivm: Salvador, 2015, p. 1000.

${ }^{43}$ Idem, p. 1003.

${ }^{44}$ LUHMANN, Niklas. Introducción a lateoría de sistemas. Lecciones publicadas por Javier Torres Nafarrete. Guadalajara: Barcelona: Anthropos, 1996, p. 61.
} 
A SUPRACONSTITUCIONALIDADE DOS TRATADOS INTERNACIONAIS SOBRE DIREITOS HUMANOS: A SUPERAÇÃO DO MODELO CONSTITUCIONALISTA MODERNO E DA SOBERANIA DO ESTADO

Estados Unidos da América e sua “Doutrina Truman”. Após testemunharem as atrocidades praticadas durante a $2^{\mathrm{a}}$ Guerra Mundial pelas forças nazistas e se depararem com o surgimento da União Soviética como potência antagônica de seus interesses políticos e econômicos, os Estados Unidos depreenderam esforços para manter os países latino-americanos sob sua área de influência e alinhamento ideológico político ${ }^{45}$.

A atuação norte-americana e os temores causados pela polarização mundial entre capitalistas e comunistas, desencadearam ondas de revoluções e golpes pela tomada do poder político, desestabilizando as instituições democráticas do continente.

Pois mesmo na América Latina as grandes forças da mudança política eram políticos civis - e exércitos. A onda de regimes militares direitistas que começou a inundar grandes partes da América do Sul na década de 1960 - o governo militar jamais saíra de moda na América Central, com exceção do México revolucionário e da pequena Costa Rica, que na verdade aboliu seu exército após uma revolução em 1948 - não respondia, basicamente, a rebeldes armados. $\mathrm{Na}$ Argentina, eles derrubaram o caudilho populista Juan Domingo Perón (18951974), cuja força estava na organização dos trabalhadores e na mobilização dos pobres (1955), após o que se viram retomando o poder a intervalos, pois o movimento de massa peronista se revelou indestrutível e não se pôde construir nenhuma alternativa civil estável. ${ }^{46}$

Nesse cenário, a República Federativa do Brasil, país de importância estratégica reconhecida pelo governo norte-americano, vivenciou a tomada do poder e a instalação de um regime militar autoritário que se apresentava como solução para combater os focos de levantes socialistas que começavam a surgir em seu território.

As Forças Armadas tomaram o poder no Brasil em 1964 contra um inimigo bastante semelhante: os herdeiros do líder populista brasileiro Getúlio Vargas (1883-1954), que se deslocavam para a esquerda no início da década de 1960 e ofereciam democratização, reforma agrária e ceticismo em relação à política americana. As pequenas tentativas de guerrilha de fins da década que proporcionaram uma desculpa para a implacável repressão do regime jamais representaram um verdadeiro desafio a ele; mas deve-se dizer que após o início da década de 1970 o regime começou a relaxar e devolveu o país a um governo civil em $1985 .{ }^{47}$

Apesar de o continente americano estar sob o domínio da intervenção dos militares, surge, no seio da Organização dos Estados Americanos (OEA), a elaboração de uma convenção sobre direitos humanos, cuja previsão de criação estava no Protocolo de Buenos Aires de 1976, em seu artigo 106, fine: “(...) Uma convenção interamericana sobre direitos humanos

\footnotetext{
${ }^{45}$ HOBSBAWN, Eric. Era dos extremos: o breve século XX: 1914-1991. $2^{\text {a }}$ Edição. $38^{\text {a }}$ Reimpressão. São Paulo: Companhia das Letras, 1995, p. 429.

${ }^{46}$ Idem. p. 429.

${ }^{47}$ Ibidem. p. 429.
} 
A SUPRACONSTITUCIONALIDADE DOS TRATADOS INTERNACIONAIS SOBRE DIREITOS HUMANOS: A SUPERAÇÃO DO MODELO CONSTITUCIONALISTA MODERNO E DA SOBERANIA DO ESTADO

estabelecerá a estrutura, a competência e as normas de fundamento da referida Comissão, bem como as dos outros órgãos encarregados de tal matéria".

Em 1967, o anteprojeto da Convenção foi elaborado pela Comissão Interamericana de Direitos Humanos. Em 1969, ocorreu a Conferência Interamericana Especializada sobre Direitos Humanos (em San José da Costa Rica, de 7 a 22 de novembro de 1969), sendo adotado o texto da Convenção Americana de Direitos Humanos em 22 de novembro de 1969, que recebeu, assim, o apelido de "Pacto de San José da Costa Rica".

Chama a atenção o contexto histórico no qual a Convenção foi elaborada. Muitos Estados americanos estavam sob o jugo de governos ditatoriais, com exceção de Cuba, cujo governo havia sido suspenso da OEA em 1962.

No caso brasileiro, a repressão política e a violência do regime vicejavam. Em 1968, a ditadura havia editado o Ato Institucional n. 5, de 13 de dezembro de 1968, pelo qual a repressão se autoconcedeu poderes absolutos e fechou o Congresso Nacional. Esse ato formalizou o arbítrio, o abuso e a violação de direitos. ${ }^{48}$

A mesma Ditadura Militar brasileira, sob o comando do General Presidente Emílio Garrastazu Médici, enviou representantes à Conferência de San José da Costa Rica, que foram recebidos normalmente pela OEA e participaram das discussões e votações. Médici, ao longo de seu mandato, tornou-se símbolo de violações maciças de direitos humanos do regime militar, tendo ocorrido em seu governo a prática de desaparecimento forçado e crimes contra a humanidade. ${ }^{49}$

Enquanto que, na Europa Ocidental, a Convenção Europeia de Direitos Humanos surgiu a partir dos esforços dos Estados Democráticos em demonstrar sua diferença em relação a ditaduras, a Convenção Americana nasceu do esforço de ditaduras em aparentar sua semelhança com Estados Democráticos. Esse contexto explica as dificuldades iniciais para implementar a Convenção, uma vez que sua redação era mais fruto da retórica do que da real adesão ao universalismo, indivisibilidade e interdependência dos direitos humanos. ${ }^{50}$

Nesse paradoxo, curiosa a manifestação da Delegação Brasileira que participou daquela Conferência Especializada em San José:

O governo do Brasil participa da Conferência Especializada Interamericana sobre Direitos Humanos movido por sua fidelidade ao princípio de respeito as direitos humanos e liberdade fundamentais consagradas nas Cartas das Nações Unidas e

\footnotetext{
${ }^{48}$ RAMOS, André de Carvalho. Processo internacional de direitos humanos. 4. ed. - São Paulo: Saraiva, 2015, p. 218.

49 RAMOS, André de Carvalho. Op. Cit., p. 218.

50 Idem, p. 219.
} 
da Organização dos Estados Americanos. O mesmo principio foi desenvolvido pela Declaração Americana de Direitos e Deveres do homem, aprovada pelo voto brasileiro, como uma aspiração de todos os povos e governos deste continente. [...] Por outro lado, juristas brasileiros têm dado sua colaboração para resolver os complexos problemas resultantes da necessidade de conciliar a proteção internacional dos direitos humanos com os devedores do Estado moderno, entre os quais figura a preservação da democracia e da ordem interna contra os que pretendem transformar a violência e o crime em instrumentos de ação política. $\mathrm{Na}$ verdade, um dos desafios que afrontam as gerações atuais é escolher as fórmulas mais apropriadas à harmonização da liberdade com a autoridade, de maneira que seja possível alcançar as reformas reclamadas pelas novas circunstâncias da era nuclear espacial sem sacrificar as conquistas espirituais de nossa civilização e as prerrogativas inerentes ao ser humano. [...] 0 desenvolvimento econômico é inseparável do social, do político e do jurídico, o que requer dos meios de integração e cooperação regional que não se esqueçam da natureza global destas metas. As observações e emendas oferecidas pela Delegação do Brasil não representação a posição final de seu Governo, nem assumes compromissos definitivos. Tratando-se de um instrumento sujeito à ratificação, é óbvio que meu país se reserva a faculdade de tomar suas decisões depois de conhecer o conjunto da convenção que seja aprovada. ${ }^{51}$

O Brasil demorou em ratificar a Convenção, mesmo após a redemocratização. O Presidente Sarney encaminhou mensagem para o Congresso Nacional, solicitando a aprovação do Pacto em 1985. Somente em 26 de maio de 1992 foi editado o Decreto Legislativo $n^{\circ} 27$, que aprovou o texto. 0 país depositou a carta de adesão à Convenção em 25 de setembro de 1992, com a consequente promulgação do Decreto nº 678 em 6 de novembro de 1992. Essa lentidão é

\footnotetext{
${ }^{51}$ Conferencia Especializada Interamericana sobre Derechos Humanos. San José, Costa Rica 7-22 de noviembre de 1969. Organización de los Estados Americanos. Washington, D.C. Secretaria General. Actas y documentos. OEA/Ser.K/XVI/1.2. Disponível em: https://www.oas.org/es/cidh/mandato/Basicos/ActasConferencia-Interamericana-Derechos-Humanos-1969.pdf. Acessado em 18/09/2015. Do original: “El Gobierno del Brasil participa de la Conferencia Especializada Interamericana sobre Derechos Humanos movido por su fidelidad al principio de respeto a los derechos humanos y libertades fundamentales consagradas en las Cartas de las Naciones Unidas y de la Organización de los Estados Americanos. El mismo principio fue desarrollado por la Declaración Americana de Derechos y Deberes del Hombre, aprobada por el voto brasileño, como una aspiración de todos los pueblos y gobiernos de este continente. (...) Por otro lado, juristas brasileños han dado su colaboración para resolver los complejos problemas resultantes de la necesidad de conciliar la protección internacional de los derechos humanos con los deberes del Estado moderno, entre los cuales figura la preservación de la democracia y del orden interno contra los que pretenden transformar la violencia y el crimen en instrumentos de acción política. En verdad, uno de los desafíos que afrontan las generaciones actuales es elegir las fórmulas más apropiadas a la armonización de la libertad con la autoridad, de manera que sea posible alcanzar las reformas reclamadas por las nuevas circunstancias de la era nuclear espacial sin sacrificar las conquistas espirituales de nuestra civilización y las prerrogativas inmanentes al ser humano. (...) El desarrollo económico es inseparable del social, del político y del jurídico, lo que requiere de los medios de integración y cooperación regional que no olviden la naturaleza global de estas metas. Las observaciones y enmiendas ofrecidas por la Delegación del Brasil no representan la posición final de su Gobierno, ni entrañan compromisos definitivos. Tratándose de un instrumento sujeto a ratificación, es obvio que mi país se reserva la facultad de tomar sus decisiones después de conocer el conjunto de la convención que sea aprobada".
} 
A SUPRACONSTITUCIONALIDADE DOS TRATADOS INTERNACIONAIS SOBRE DIREITOS HUMANOS: A SUPERAÇÃO DO MODELO CONSTITUCIONALISTA MODERNO E DA SOBERANIA DO ESTADO

explicada pelo processo brasileiro de transição política. Ainda reinava no país a abertura democrática lenta, gradual e segura.

Nesse interregno, sobreveio a novel ordem constitucional brasileira em 1988. Desde sua redação original, consta, no art. $5^{\circ}$, o $\$ 2^{\circ}$, in verbis: os direitos e garantias expressos nesta Constituição não excluem outros decorrentes do regime e dos princípios por ela adotados, ou dos tratados internacionais em que a República Federativa do Brasil seja parte. Atualmente, a doutrina internacionalista pátria posiciona-se, majoritariamente, em defesa da hierarquia constitucional dos tratados internacionais sobre direitos humanos, seja por conta da incorporação material $\left(\$ 2^{\circ}\right)$, seja pela incorporação formal $\left(\$ 3^{\circ} \text {, incluído pela EC } n^{\circ} 45 / 2004\right)^{52}$. Por sua vez, prevalece na jurisprudência do Supremo Tribunal Federal ${ }^{53}$ a tese da hierarquia supralegal dos tratados internacionais sobre direitos humanos não incorporados pelo procedimento previsto no $\$ 3^{\circ}$, do art. $5^{\circ}$, da CF/88.

Todavia, deve-se reconhecer a supraconstitucionalidade dos tratados internacionais sobre direitos humanos, pois, além de derivarem de norma cogente do direito das gentes (jus cogens), derivam do texto convencional de alguns tratados e da jurisprudência da Corte Interamericana de Direitos Humanos.

Com relação à origem no direito das gentes, Ramos leciona:

No Direito Internacional, a norma imperativa em sentido estrito (também denominada norma cogente ou norma de jus cogens) é aquela que contém valores considerados essenciais para a comunidade internacional como um todo, e que, por isso, possui superioridade normativa no choque com outras normas de Direito Internacional. Assim, pertencer ao jus cogens não significa ser considerado norma obrigatória, pois todas as normas internacionais o são: significa que, além de obrigatória, a norma cogente não pode ser alterada pela vontade e um Estado. A derrogação da norma imperativa só pode ser feita por norma de igual quilate, ou seja, por norma também aprovada pela comunidade internacional como um todo. A vontade isolada de um Estado ou de um grupo de Estados, então, não pode ofender uma norma cogente internacional. ${ }^{54}$

A Convenção Internacional sobre o Direito dos Tratados de Viena, de 1969, internalizado pelo Decreto $n^{\circ} 7.030$, de 14 de dezembro de 2009, explicita o conceito de jus cogens ou norma imperativa de Direito Internacional, em seus artigos 27, 53, 64 e 71.

\footnotetext{
${ }^{52}$ Nesse sentido, Cf. PIOVESAN, Flávia; MAZZUOLLI, Valério de Oliveira; RAMOS, André de Carvalho.

${ }^{53}$ Cf. STF, RHC 79.785/RJ, HC 90.172/SP, RE 466.343, HC 98.893/SP.

${ }^{54}$ RAMOS, André de Carvalho. Teoria geral dos direitos humanos na ordem internacional. 4. Ed. São Paulo: Saraiva, 2014, p. 152-153.
} 
A SUPRACONSTITUCIONALIDADE DOS TRATADOS INTERNACIONAIS SOBRE DIREITOS HUMANOS: A SUPERAÇÃO DO MODELO CONSTITUCIONALISTA MODERNO E DA SOBERANIA DO ESTADO

0 artigo 27 deve ser expressamente mencionado, pois corrobora a defesa da supraconstitucionalidade dos tratados internacionais sobre direitos humanos: “Direito Interno e Observância de Tratados - Uma parte não pode invocar as disposições de seu direito interno para justificar o inadimplemento de um tratado. Esta regra não prejudica o artigo 46".

Se o Estado brasileiro, no exercício de sua soberania, ratificou e internacionalizou a Convenção de Viena, incorporou a tese de que não pode invocar, nem mesmo disposições constitucionais para justificar o fato de não estar observando as regras previstas em um tratado internacional. Como dito, esse ponto salienta o reconhecimento da natureza supraconstitucional dos tratados sobre direitos humanos. Se analisada a disposição do Tratado de Viena em conjunto com 0 artigo $5^{\circ}, \$ 2^{\circ}$, da $\mathrm{CF} / 88$, percebe-se que a norma fundamental brasileira reconhece a influência dos tratados internacionais sobre direitos humanos. Ao tratar dos direitos humanos como normas de jus cogens, Ramos assevera:

Conclui-se que os direitos humanos constituem o núcleo essencial de normas que compõe o ordenamento jurídico internacional contemporâneo e, então, a norma de direitos humanos é norma hierarquicamente superior no ordenamento, que seja pelo critério material (conteúdo) ou pelo critério formal (norma de jus cogens). As consequências de tal qualidade de jus cogens das normas protetoras de direitos fundamentais não são meramente teóricas. Tratados tradicionais, como os de extradição, podem ser considerados ofensivos ao jus cogens por terem violado direitos fundamentais do extraditando. Mesmo condutas unilaterais dos Estados ou coletivas, adotadas no seio de organizações internacionais, podem ser confrontadas com o respeito às normas de jus cogens. ${ }^{55}$

Gonçalves (2013, p. 401) lembra que a doutrina latino-americana majoritária defende a adoção do princípio da supremacia da Convenção Americana de Direitos Humanos, extraindo-a do seu artigo $2^{\circ}$, in verbis:

Artigo $2^{\circ}$ - Dever de adotar disposições de direito interno. Se o exercício dos direitos e liberdades mencionados no artigo 1 ainda não estiver garantido por disposições legislativas ou de outra natureza, os Estados-partes comprometem-se a adotar, de acordo com as suas normas constitucionais e com as disposições desta Convenção, as medidas legislativas ou de outra natureza que forem necessárias para tornar efetivos tais direitos e liberdades. ${ }^{56}$

Semelhantes disposições são encontradas no Pacto Internacional sobre Direitos Civis e Políticos (Decreto $n^{\circ}$ 592, de 6 de julho de 1992) e no Pacto Internacional sobre Direitos Econômicos, Sociais e Culturais, in verbis, respectivamente:

${ }^{55}$ RAMOS, André de Carvalho. Op. Cit., p. 168.

56 GONÇALVES, Vinícius de Almeida de Almeida. A figura do bloco de convencionalidade nas decisões proferidas pela corte interamericana de direitos humanos. In: Revista Eletrônica do Curso de Direito da Universidade Federal de Santa Maria. V. 8, n. 2/2013, p. 401. 
A SUPRACONSTITUCIONALIDADE DOS TRATADOS INTERNACIONAIS SOBRE DIREITOS HUMANOS: A SUPERAÇÃO DO MODELO CONSTITUCIONALISTA MODERNO E DA SOBERANIA DO ESTADO

2.2. Na ausência de medidas legislativas ou de outra natureza destinadas a tornar efetivos os direitos reconhecidos no presente Pacto, os Estados Partes do presente Pacto comprometem-se a tomar as providências necessárias com vistas a adotá-las, levando em consideração seus respectivos procedimentos constitucionais e as disposições do presente Pacto.

2.1. Cada Estado Parte do presente Pacto compromete-se a adotar medidas, tanto por esforço próprio como pela assistência e cooperação internacionais, principalmente nos planos econômico e técnico, até o máximo de seus recursos disponíveis, que visem a assegurar, progressivamente, por todos os meios apropriados, o pleno exercício dos direitos reconhecidos no presente Pacto, incluindo, em particular, a adoção de medidas legislativas.

Por sua vez, a jurisprudência da Corte Interamericana de Direitos Humanos, no exercício do controle de convencionalidade por ela exercido, revela a adoção da hierarquia supraconstitucional do Pacto de San José em relação aos Estados-partes. O alcance deste controle é tão forte que a Corte Interamericana chegou inclusive a declarar a responsabilidade internacional pela existência de normas constitucionais contrárias à Convenção.

\begin{abstract}
Sem embargo, o controle de convencionalidade permite que a Corte Interamericana interprete e aplique a Convenção por meio de um exame de confrontação com o direito interno, podendo este ser uma lei, um ato administrativo, jurisprudência e práticas administrativas e judiciais, e até mesmo a Constituição. É possível, portanto, que um Estado-parte seja condenado pela Corte Interamericana de Direitos Humanos a revogar leis incompatíveis com a Convenção ou adaptar suas legislações através de reformas constitucionais para que se garanta a tutela de direitos humanos no âmbito do direito interno. ${ }^{57}$
\end{abstract}

Nesse cenário, se os tratados internacionais sobre direitos humanos, como o Pacto de San José e os Pactos Internacionais da ONU, preveem a exigência de os Estados adotarem as medidas legislativas necessárias, sejam elas infraconstitucionais ou constitucionais, e se um Estado-parte pode ser responsabilizado internacionalmente pela Corte Interamericana pelo fato de sua Constituição violar os direitos previstos naquele Tratado, não há dúvida que os Estados, ao ratificarem esses tratados e ao se submeterem à jurisdição contenciosa daquela Corte, reconhecem a supraconstitucionalidade desses documentos internacionais e abrem mão de parte de sua soberania normativa.

\footnotetext{
${ }^{57}$ GUERRA, Sidney. A proteção internacional dos direitos humanos no âmbito da Corte Interamericana e o controle de convencionalidade. In: Nomos: Revista do Programa de Pós-Graduação em Direito da Universidade Federal do Ceará. V. 32, n. 2, 2012, p. 361-362.
} 


\section{CONCLUSÃO}

A construção moderna do Estado conduziu ao necessário reconhecimento da soberania como preceito fundamental da organização orgânica e normativa de um povo sobre determinado território. A necessidade da independência e do reconhecimento no cenário internacional fez com que os Estados erguessem barreiras normativas em suas fronteiras, negando os valores universais que unem todos os povos.

Os valores superiores de ética e moral, reunidos num conceito superior e anterior à própria existência do Estado, exigem que os Estados repensem sua posição perante seus pares. Toda a construção teórica da legitimidade material da teoria constitucional e da soberania devem ser reanalisadas com cuidado.

Deve-se lembrar o que Celso Lafer leciona, para quem os direitos humanos "podem ser considerados um 'adquirido axiológico' de alcance universal. Esse 'universal', dadas as rupturas e descontinuidades que caracterizam o processo histórico, é fugidio. Indica o melhor caminho e aponta que o seu descumprimento leva, para recorrer à metáfora de Bobbio sobre o papel da razão, a becos sem saída". ${ }^{58}$

Se a comunidade internacional como um todo reconhece a existência de valores essenciais que não podem ser derrogados por outros tratados, a não ser que sejam também oriundos do jus cogens, deve-se compreender que esse reconhecimento se espalha para toda e qualquer conduta dos Estados, inclusive quando da negação do status superior dos tratados internacionais sobre direitos humanos.

Compreender os tratados internacionais sobre direitos humanos como ordens jurídicas supraconstitucionais pode revelar-se como premissa teórica e prática necessária no atual contexto de restrição e limitação da atuação do Estado e na proteção externa e interna dos direitos humanos. Os litigantes nacionais podem se aproveitar da redação genérica das normas de direitos humanos e da força expansiva de seus comandos para consagrar uma jusfundamentalização das lides, situações nas quais os direitos humanos podem ser invocados e que forçam os Tribunais a decidir de acordo com o tratado internacional invocado que vincula a maneira com que se deve interpretar e suprimir eventuais lacunas existentes no corpo da Constituição.

58 LAFFER, Celso. Comércio, desarmamento, direitos humanos: reflexões sobre uma experiência diplomática. São Paulo: Paz e Terra, 1999, p. 200. 
A defesa da supraconstitutcionalidade não objetiva fins sofistas ou retóricos, tampouco fantasiosos ou mesquinhos. Visa estabelecer um marco inicial na compreensão dos futuros estágios de desenvolvimento dos Estados nacionais soberanos. Uma vez aceita a supraconstituticonalidade dos tratados internacionais sobre direitos humanos, pode-se partir para a compreensão e análise dos desdobramentos desse status normativo a eles conferido.

Com o reconhecimento da supraconstitucionalidade dos tratados internacionais sobre direitos humanos, pode-se, efetivamente, avançar de um Estado Democrático de Direito, para um Estado Democrático e Humanitário de Direito Internacional.

\section{REFERÊNCIAS}

ALVES, Fernando de Brito. Constituição e participação popular: a construção históricodiscursiva do conteúdo jurídico-político da democracia como direito fundamental. Curitiba: Juruá, 2013.

ARON, Raymond. Paz e guerra entre as nações. Tradução de Sérgio Bath. 2. Ed. Brasília: UnB, 1996.

BOBBIO, Norberto. A era dos direitos. Rio de Janeiro: Campus, 2004.

BOBBIO, Norberto. Estado, governo e sociedade: para uma teoria geral da política. Tradução: Marco Aurélio Nogueira. Rio de Janeiro: Paz e Terra, 1995.

BODIN, Jean. Los seis libros de la república. 2. Ed. Tradução: Pedro Brava Gala. Madrid: Tecnos, 1992, I, 8.

BONAVIDES, Paulo. Ciência política. 16. Ed. Malheiros Editores: São Paulo, 2010.

BOSON, Gerson de Brito Mello. Direito Internacional Público: o Estado em direito das gentes. Belo Horizonte: Del Rey, 1994.

COKE, Sir Edward. Parliamentary History. 1627. London: 11.

COLOMBO, Silvana. A relativização do conceito de soberania no plano internacional. Argumenta: Revista do Programa de Mestrado em Ciência Jurídica da Universidade Estadual do Norte do Paraná - UENP. № 17. Jacarezinho/PR, 2012.

COMPARATO, Fábio Konder. Fundamentos dos direitos humanos. Revista Consulex, v. 48, 2000.

DALLARI, Dalmo de Abreu. O futuro do Estado. 2. Ed. São Paulo. Saraiva, 2007.

DWORKIN, Ronald. Uma questão de princípio. São Paulo: Martins Fontes, 2000, p. 90.

FERNANDEZ, Eusebio. Teoría de la justicia y derechos humanos. Madrid: Debate, 1984. 
FERRAJOLI, Luigi. A soberania no mundo moderno. São Paulo: Martins Fontes, 2003.

GONÇALVES, Vinícius de Almeida de Almeida. A figura do bloco de convencionalidade nas decisões proferidas pela corte interamericana de direitos humanos. Revista Eletrônica do Curso de Direito da Universidade Federal de Santa Maria. V. 8, n. 2/2013. ISS 1981-3694.

GUERRA, Sidney. A proteção internacional dos direitos humanos no âmbito da Corte Interamericana e o controle de convencionalidad, V. 32, n. 2, 2012.

HART, Herbert Lionel Adolphus. O conceito de direito. 2. Ed. Tradução: A. Ribeiro Mendes. Lisboa: Fundação C., 1988.

HELLER, Hermann. Teoría del Estado. 2. Ed. México, Fondo de Cultura Económica, 1947. Gulbenkian, 1994.

HOBSBAWN, Eric. Era dos extremos: o breve século XX: 1914-1991. 2ª Edição. 38 Reimpressão. São Paulo: Companhia das Letras, 1995

KELSEN, Hans. Teoría general del Estado. Traducción: Eduardo Gacía Máynez. Universidade Nacional Autónoma de México, 1988.

- Teoria pura do direito. Tradução de João Baptista Machado. 6. Ed. Coimbra: Arménio Amado, 1984. 484p. (Coleção Stvdivm; Temas filosóficos, jurídicos e sociais).

LAFFER, Celso. A reconstrução dos direitos humanos: um diálogo com o pensamento de Hannah Arendt. In: Estudos avançados. São Paulo: Companhia das Letras, 1991.

LAFFER, Celso. Comércio, desarmamento, direitos humanos: reflexões sobre uma experiência diplomática. São Paulo: Paz e Terra, 1999.

LASSALE, Ferdinad. Que é uma constituição? São Paulo: Edições e Publicações Brasil, 2006.

LUHMANN, Niklas. Introducción a lateoría de sistemas. Lecciones publicadas por Javier Torres Nafarrete. Guadalajara: Barcelona: Anthropos, 1996.

MCILWAIN, Charles Howard. Constitucionalismo antiguo y moderno. Traducción: Juan José Solozábal Echavarría. Centro de Estudios Constitucionales: Madrid, 1991.

PIOVESAN, Flávia. Direitos humanos e justiça internacional: um estudo comparativo dos sistemas regionais europeu, interamericano e africano. 5. Ed. rev., ampl. e atual. 2. Tiragem. São Paulo: Saraiva, 2014.

PORTELA, Paulo Henrique Gonçalves. Direito internacional público e privado: incluindo noções de direitos humanos e de direito comunitário. 7. Ed. rev., ampl., e atual. Editora Juspodivm: Salvador, 2015.

RAMOS, André de Carvalho. Processo internacional de direitos humanos. 4. ed. - São Paulo: Saraiva, 2015. 
ISSN 1981-3694

(DOI): $10.5902 / 1981369419960$

REVISTA ELETRÔNICA DO CURSD DE

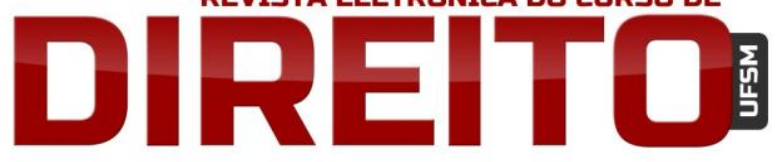

A SUPRACONSTITUCIONALIDADE DOS TRATADOS INTERNACIONAIS SOBRE DIREITOS HUMANOS: A SUPERACC̃̃O DO MODELO CONSTITUCIONALISTA MODERNO E DA SOBERANIA DO ESTADO

RAMOS, André de Carvalho. Teoria geral dos direitos humanos na ordem internacional. 4. Ed. São Paulo: Saraiva, 2014.

ROUSSEAU, Jean Jacques. Do contrato social: Princípios do direito político. São Paulo: Revista dos Tribunais, 2003.

SCHMITT, Carl. Teoría de La Constitución. Presentación de Francisco Ayala. Primera edición en “Alianza Universidad Textos" 1982. Cuarta reimpresión em "Alianza Universidad Textos". Madrid. España. 2003.

TEIXEIRA, José Horário Meirelles. Curso de direito constitucional. Rio de Janeiro: Forense, 1991. VIEIRA DE ANDRADE, José Carlos. Os direitos fundamentais na Constituição portuguesa de 1976. Coimbra: Livr. Almedina, 1983.

Recebido em: 13/10/2015 / Revisões requeridas em: 10/12/2015 / Aprovado em: 16/12/2015 